\title{
Formação humana e social a partir da escola
}

\author{
Rita de Cássia de Souza \\ Universidade Federal de Viçosa (Brasil)
}

\section{Resumo}

Este artigo apresenta uma escola que busca uma formação integral para seus estudantes e que tem um plano de trabalho inovador a começar pelo compromisso de transformação social que teve início com a decisão de construí-la numa região de baixos recursos econômicos da cidade de Mérida, no México. Realizamos uma pesquisa qualitativa e descritiva, partindo de um referencial construcionista social, que recomenda que os participantes sejam coautores do trabalho, evitando o distanciamento pesquisador-pesquisado. Neste sentido, convivemos alguns dias dos meses de setembro e outubro de 2018 na escola, participando de aulas e outras atividades e fizemos diálogos gravados com três professores sobre o trabalho da escola. Concluímos que a escola possui um trabalho de formação social e humana que se dá a partir de uma matriz curricular diferenciada, com disciplinas que buscam articular seus conteúdos à realidade dos estudantes, incluindo matérias de formação pessoal, social, profissional e realização de atividades socio comunitárias pelos estudantes.

Palavras-chave: Educação integral. Ensino médio. Formação social e humana. Construcionismo social.

\section{Human and social formation from school}

\section{Abstract}

This article presents a school that seeks an integral formation for its students and that has an innovative work plan beginning with the commitment of social transformation that began with the decision to construct it in a region of low economic resources of the city of Mérida, in the Mexico. We conducted a qualitative and descriptive research, starting from a social constructionist referential, which recommends that the participants be coauthors of the work, avoiding the researcher-researched distancing. In this sense, we live together some days of the months of September and October of 2018 in the school, participating in classes and other activities and we recorded dialogues with three teachers on the work of the school. We conclude that the school has a work of social and human formation that takes place from a differentiated curricular matrix, with disciplines that seek to articulate their contents to the reality of the students, including personal, social, professional and students' realization of social community.

Keywords: Integral education. High school. Social and human formation. Social construccionism. 
Formação humana e social a partir da escola

\section{Formación humana y social desde la escuela}

\section{Resumen}

Este artículo presenta una escuela que busca una formación integral para sus estudiantes y que tiene un plan de trabajo innovador a comenzar por el compromiso de transformación social que comenzó con la decisión de construirla en una región de bajos recursos económicos de la ciudad de Mérida, México. Realizamos una investigación cualitativa y descriptiva, partiendo de un referencial construccionista social, que recomienda que los participantes sean coautores del trabajo, evitando el distanciamiento investigador-investigado. En este sentido, convivimos algunos días de los meses de septiembre y octubre de 2018 en la escuela, participando en clases y otras actividades y grabamos diálogos con tres profesores sobre el trabajo de la escuela. Concluimos que la escuela posee un trabajo de formación social y humana que se da a partir de una matriz curricular diferenciada, con disciplinas que buscan articular sus contenidos a la realidad de los estudiantes, incluyendo materias de formación personal, social, profesional y realización de actividades socio-comunitarias por los estudiantes.

Palabras-clave: Educación integral. Bachillerato. Formación social y humana. Construccionismo social.

objetivo deste artigo' é apresentar uma escola que busca uma 2 formação integral para seus estudantes e tem um trabalho diferenciado que começou pela decisão de construíla em uma região de baixos recursos econômicos da cidade de Mérida, no México.

A escola ${ }^{2}$, denominada UABIC - Unidade Acadêmica Bacharelado com Interação Comunitária - é vinculada à UADY, Universidade Autônoma de Yucatán, uma universidade pública, reconhecida pela qualidade de sua formação a nível superior e médio, pois a Universidade tem três escolas, conhecidas como Preparatórias (chamadas "prepas") 1, 2 e 3, que oferecem una educação de grande qualidade e preparam muitos estudantes para o nível superior.

Para estudar nestas "prepas"3 1 e 2 da UADY, é necessário ser aprovado em uma avaliação com uma grande concorrência, que exclui a maioria dos estudantes. Quando a Universidade estava para criar a terceira escola de ensino médio, decidiu construíla em uma região de baixos recursos econômicos, dando oportunidade a estudantes em uma área onde as únicas escolas de ensino médio existentes são técnicas. Por si só, esta já seria uma iniciativa inovadora, no entanto, a UADY partia do princípio de que não bastava abrir a escola naquele local. Era preciso planejar toda uma formação diferenciada para que os estudantes não somente pudessem ter acesso a uma escola de 
grande qualidade e exigência e concluir o ensino médio com possibilidade de chegar à universidade, assim como era importante criar um projeto buscando ajudar a mudar uma realidade de desigualdade social, econômica e cultural. É justamente este projeto de uma escola que contribui para a transformação pessoal e social de uma comunidade desfavorecida que pretendo presentar aqui.

Foi realizada uma pesquisa qualitativa e descritiva, partindo de um referencial construcionista social: "La idea fundamental de la construcción social parece bastante sencilla, pero es a la vez profunda: todo lo que consideramos real ha sido construido socialmente. $\bigcirc$ lo que es más radical, nada es real hasta que la gente se ponga de acuerdo que lo es" (GERGEN; GERGEN, 201 1 , p. 13). Isso significa dizer que não apresentamos aqui como é a escola, e sim como ela nos pareceu em nosso encontro e a partir dos diálogos construídos com os professores. Neste sentido, não fizemos entrevistas, mas sim diálogos:

El dialogismo también propone el carácter múltiple de la autoría de la generación del sentido. Los puntos de vista filosóficos del autor no ocupan el primer lugar. Los personajes parecen liberarse de la tutela de su creador. Poseen una autoridad ideológica y son independientes. Son personas libres, capaces de encarar a su creador, de no estar de acuerdo con él y hasta de oponérsele (INFANTE, 2013 , p. 111 .

Ao fazer uma pesquisa relacional, buscamos criar um espaço de liberdade para dialogar com nossos colaboradores como bons anfitriões. Segundo Anderson (2012): ser um anfitrião é ser amável; participar na conversação, não a conduzir; considerando que falar, escutar e ouvir são igualmente importantes para o diálogo. Os participantes são coautores dessa pesquisa, pois foram as conversações colaborativas com eles as fontes principais deste trabalho. Assim também, desde esta perspectiva: "El investigador se une con los participantes en el papel de co-respondiente, en vez de analista o intérprete posicionado encima y fuera de lo expresado por los participantes" (DEFEHER, s.d., p. 21 ).

Para construir os dados desta pesquisa, estive convivendo alguns dias dos meses de setembro e outubro de 2018 em aulas e atividades da escola e conversando com professores e estudantes, visitantes e familiares dos alunos $^{4}$, e estes foram os principais colaboradores deste trabalho: 1) Mitchel Antonio Guerrero González, graduado em Educação, professor ${ }^{5}$ fundador da UABIC, foi, de 2009 a 2015 coordenador da área de comunicação e, desde 
2015, é gestor acadêmico` da UABIC; 2) Diana Marisol Rodríguez Bastos é psicóloga e responsável pela área de tutoria, orientação e conselho educativo e também fundadora da escola; 3) Patricia del Rosario Baas Rejón é graduada em Ciências da Família, com especialização em docência e atualmente cursa um Mestrado em Psicologia da educação. É coordenadora da área de Responsabilidade Social da UABIC.

Marcamos com os participantes individualmente um horário na escola onde nos receberam em suas salas e, com a permissão de todos, gravamos, com um aplicativo de um smartphone, nossas conversações. Pedi aos participantes que se apresentassem, falassem de sua formação, sua função na escola, como tinham chegado a este trabalho, o que eles pensavam sobre e quais eram os desafios de suas atividades. As conversas duraram em torno de uma hora cada e, depois disso, fiz as transcrições e, escrito o artigo, enviei aos participantes para ler e conversamos, uma vez mais, sobre o que estavam de acordo, se tinham dúvidas, o que desejavam mudar. Incluídas as sugestões, a versão final foi enviada aos participantes para sua aprovação e da direção da escola.

Neste sentido, o que apresentamos aqui é uma construção conjunta de uma história de uma escola que faz um trabalho diferenciado de formação e que tem ambição de oferecer mais do que o ensino médio. $\bigcirc$ nome unidade acadêmica foi dado pensando que, no futuro, esta instituição possa abrigar programas de capacitação e de formação para a vida, inclusive tendo formação superior, com mestrado e doutorado.

No momento, aos sábados, professores da UADY ministram a disciplina "O Profissional e a Comunidade" para estudantes de cursos como Psicologia, Matemática e Projeto de residências e esses fazem atividades na comunidade: às vezes a comunidade vem à escola e, às vezes os estudantes saem para atender à comunidade. A UABIC é um espaço onde estudantes da UADY fazem práticas, um exemplo é atendimento de estudantes de Psicologia a pessoas da comunidade que acontece aos sábados na escola.

A UABIC começou suas atividades em setembro de 2009 com 206 estudantes e, em 2018, eram 877 e 58 professores $^{7} 16$ de ciências naturais, 4 de informática, 7 de comunicação, 12 de desenvolvimento físico, artístico e cultural, 7 de responsabilidade social, 6 de matemática, 11 de ciências sociais y humanidades e 4 de desenvolvimento humano integral). 
Segundo Diana e Mitchel, para a primeira geração, pessoas da UADY solicitaram à Secretaria de Educação Pública bases de dados de egressos da educação secundária na região e, com estes nomes, eles passaram casa por casa convidando estudantes próximos de terminar a escola secundária, ou aqueles que tinham deixado de estudar ou que estavam em outras escolas. Os estudantes que aceitaram o convite foram matriculados na escola. No entanto, houve alguns problemas: havia estudantes que não queriam estudar ou estar na escola e: "A veces teníamos aquí chicos que tenían dinero y tenían mucha facilidad económica y se destacaban de los demás de alguna manera. Era muy evidente" (MITCHEL, em conversação, 2018) ${ }^{8}$.

No ano seguinte, a escola começou a usar o EXANI I, uma avaliação aplicada pelo CENEVAL - Centro Nacional de Evaluación para la Educación Superior - associação civil cuja atividade principal é criar e aplicar instrumentos de avaliação de conhecimentos, habilidades e competências.

El EXANH es un examen que ofrece información para identificar a los aspirantes con mayor aptitud para lograr un buen desempeño en el primer ciclo escolar de la educación media superior. Se integra con dos exámenes: EXANII Admisión, que es un instrumento estandarizado de aptitud académica que evalúa conocimientos y habilidades numéricas, verbales y no verbales en áreas de la comunicación y pensamiento matemático que son predictivas del desempeño académico en el primer ciclo escolar. EXANI-I Diagnóstico, que explora conocimientos y habilidades en áreas disciplinares de la educación básica para identificar el logro académico. Es un examen de diagnóstico y la institución tiene la opción de incluirlo o no en su proceso de admisión. Verifica en la convocatoria o en servicios escolares de la institución que elegiste si lo debes presentar (EXANI I, s.d.).

A partir de 2010, portanto, passaram a ser utilizados dois critérios de seleção que eram verificados de forma paralela: o EXANI I (49\%) e um estudo socioeconômico (51\%) que deveria comprovar que o candidato tinha baixos recursos. $\bigcirc$ resultado era que o nível socioeconômico se impunha aos resultados da avaliação e eram aprovados estudantes de baixas condições econômicas, mas que não necessariamente tinham bons resultados no EXANI I. Diana nos contou de um caso específico em que um estudante chegou com um diagnóstico de déficit cognitivo e não conseguia obter boas notas e, depois de muitas reuniões com a família, a decisão conjunta foi transferi-lo para uma 
escola técnica da região. Segundo a psicóloga, este foi o único estudante que apresentou problemas cognitivos, os demais são questões emocionais e sociais.

Depois deste caso, em 2018, a escola alterou o momento em que se verificam os dois critérios: o estudo socioeconômico se realiza antes do EXANI I. Somente os candidatos que apresentam baixos recursos econômicos continuam no processo de seleção e realizam o EXANI I, e só são aprovados os alunos com melhores notas na avaliação. "Entonces ahora solamente ingresan alumnos que lo necesitan económicamente, pero con buenos resultados" (MITCHEL, em conversação, 2018).

Conversando com os estudantes do $3^{\circ}$ e último ano do ensino médio, eles disseram que, ao registrarem-se para o processo de seleção, preenchem um questionário com suas condições econômicas e que, uma vez aprovados na seleção, todos eles receberam uma visita de pessoas da UADY em suas casas buscando comprovar sua situação econômica, pois esta é uma condição fundamental para estudar na UABIC. Segundo Michel, são pessoas do Departamento de Educação Média Superior da UADY que fazem as visitas às casas para averiguar as condições socioeconômicas dos estudantes.

A princípio, a UABIC utilizava um projeto pedagógico denominado MEYA - Modelo Educativo y Académico -, porém o Departamento de Investigación e Innovación Educativa da UADY criou o MEFI - Modelo Educativo para la Formación Integral - com um enfoque por competências ${ }^{9}$, implementado a partir de 2012 a nível superior e, a partir de 2015, a nível de ensino médio em todas as escolas da UADY.

Hubo una reforma desde 2006 aquí en México que impulsó mucho ese cambio con las competencias. Entonces la idea es dejar de centrarnos en la memorización, dejar de centrarnos en un listado de contenidos probablemente sin conexión y mostrar, con los alumnos, contenidos que permitan desarrollar habilidades que les sirvan para resolver problemas, pensamiento crítico, pensamiento analítico. Que puedan ellos aplicarlos o llevarlos a un contexto, no solamente escolar, sino de fuera. Y viene marcado por algunas particularidades: el número de crédito que se había de cubrir y para el bachillerato, además, trae un eje ocupacional. La idea es que el alumno que decide no estudiar el nivel superior, o si, quiere estudiar, pero, además, requiere trabajar, tenga algunas herramientas que le permitan, de manera independiente o a través de un empleador, 
insertarse en el campo laboral. La unidad académica trabaja el eje del horticultor, de auxiliar administrativo y de administrador de medios sociales. A los chicos, durante su segundo y tercer año de bachillerato, se imparten estas asignaturas del componente ocupacional para que aprendan algunas herramientas laborales y algún oficio. Eso es un cambio principal que tuvo el MEFI, pero sin llegar a ser un bachillerato técnico. Son las herramientas mínimas que se les proporciona. Probablemente, éste sea un aspecto que hay que mejorar, pero poco a poco. Es una diferencia notable (MITCHEL, em conversação, 2018).

Outra mudança, depois da utilização do MEFl, foi a participação dos estudantes nas aulas:

Yo normalmente hago mis recorridos desde la mañana, desde tempranito, y hasta las últimas horas de clase. Yo veo, en más de la mitad de las clases, a los alumnos interesados, sobre todo a los alumnos haciendo algo. Es muy raro llegar a un salón donde el alumno esté pasivo, solamente escuchando el dictado del maestro. Sí pasa, pero es muy ocasional. Yo normalmente, cuando paso, veo que los maestros están con los equipos, están dando indicaciones, los estudiantes están levantando la mano, hacen preguntas, están haciendo algo. En unas asignaturas más que en otras, pero sí se nota un cambio en cuanto a esa dinámica. Lo que veo también es que los maestros están buscando maneras distintas de cómo llegar a los chicos porque, a pesar de todos los salones ahí proyectores, hubo una época en que no servía ningún proyector prácticamente y tuvieron que buscar la manera de hacer (MITCHEL, em conversação, 20181.

De fato, eu também percebi que os estudantes estão quase sempre em atividades em grupos. Um dia, depois de terminado o horário de aula, vi uns estudantes fazendo exercícios sobre seno e cosseno no quadro negro. Eles me disseram que o professor de matemática pediu a eles para fazer um vídeo ${ }^{10}$ deles resolvendo o exercício em grupo, o que me pareceu muito criativo, pois é muito provável que os estudantes tenham celular e isso pode ser mais interessante que somente fazer a atividade no papel.

Em uma classe de inglês de terceiro ano ${ }^{11}$ em que participei, os grupos estavam apresentando monumentos pelo mundo lquando foram criados, suas dimensões etc.) e muitos apresentaram protótipos feitos por eles com muitos 
detalhes. Perguntei à professora se ela pontuava o trabalho manual e ela me disse que os estudantes não faziam os trabalhos por pontuação, mas porque eles gostavam e que era muito comum os estudantes apresentarem trabalhos manuais elaborados. Mitchel nos contou que os estudantes da UABIC adoram fazer estas atividades:

Y lo que veo que les interesan más a nuestros alumnos de la unidad académica es cuando tienen que hacer algo manual, tienen que construir algo, hacer un prototipo, un cartel, si ellos se involucran en hacer recortes, pegar, si les gusta mucho este trabajo. Incluso ha habido reportes donde dejan de hacer otras actividades por hacer la actividad donde les pide construir algo. Aparte, yo veo que les llama mucho la atención (MITCHEL, em conversação, 2018).

Na Jornada de Ciência, Cultura e Tecnologia, em outubro de 2018, houve um concurso de altares para o dia dos mortos que premiava os altares que mais representavam a tradição yucateca do Hanal Pixán, nome que significa "comida das almas". Esta é uma tradição do povo maia (grupo indígena que mora na região) e agora dos mexicanos em geral, que vem da crença de que entre os dias 31 de outubro a 2 de novembro, as almas "recebem permissão" para visitar sus familiares e estes preparam um altar com comidas, bebidas e objetos que lembram a pessoa falecida. Na escola, cada sala de aula preparou seu altar e fez uma apresentação a duas pessoas de fora da escola que pontuavam as atividades, tendo como critérios os mais tradicionais e representativos da cultura yucateca. $\bigcirc$ altar ganhador representaria a escola em um concurso com todos os cursos da UADY, e, deste grupo, sairia um vencedor que receberia um prêmio em dinheiro. 


\section{Imagens de atividades realizadas pelos estudantes da UABIC}

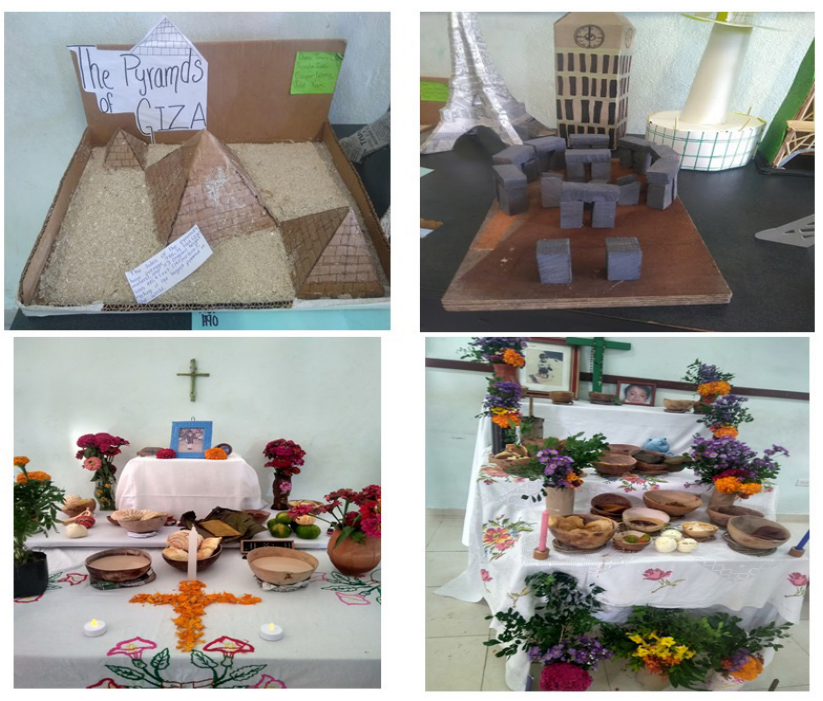

Fotos: 1 e 2) Materiais apresentados por estudantes do 30 ano em uma classe de inglês em setembro de 2018. Fotos: 3 e 4) Altares apresentados pelos estudantes na escola para o concurso do Hanal Pixán.

Para o gestor acadêmico, além das atividades em grupo, com mais participação dos estudantes, outra vantagem do MEFI foi o aumento de estudantes que terminam o ensino médio na UABIC, havendo menor evasão e reprovação. Ele disse que, em junho de 2018, 85\% dos estudantes da UABIC terminaram o ensino médio. Antes do MEFI, entravam 300 e o máximo de alunos que concluíam era 135, havendo mais de 50\% de evasão. Antes de chegar ao terceiro ano, muitos alunos já tinham deixado a escola, cerca de 80 a 90 alunos deixavam de estudar. Perguntei, então, o que os estudantes justificavam para sair da escola.

No quisiera generalizar, pero algunos casos que me han llegado eran cuestiones económicas de no poder seguir, por el pasaje del camión, o por la comida, por cuestiones de que los papás prefieren meterlo a trabajar para que apoyen la casa. Algunos pocos casos de embarazo, muy pocos, un caso por cada generación, más o menos. Pero, principalmente, es el factor económico, incluso ellos, cuando empiezan a trabajar en ocasiones, durante vacaciones, ya no regresan porque ya empezaron a ganar dinero y en casa ellos 
están viendo que pueden ayudar a mamá o a papá o a sus hermanitos y prefieren seguir trabajando y dejan de venir (MITCHEL, em conversação, 20181.

A resposta não explica porque o MEFI aumentou a oportunidade de os estudantes terminarem o ensino médio, então perguntei se a mudança para que os alunos se mantivessem na escola foi em suas condições econômicas.

No ha mejorado mucho el nivel económico. De manera interna, a la misma escuela trata de solventar muchas cosas con los alumnos. Aquí es muy común, si usted se acercara a los cerca de 50 maestros que hay, estoy seguro que al menos 40 han sacado de su bolsillo para apoyar al alumno. Si los alumnos no traen sus copias porque no la pueden imprimir, yo les doy porque me interesa que lean, me interesa que hagan la tarea. Para los que se reprueban en materias, tienen que recursar. Esos ya son horarios más tarde y el alumno está desde las 7 y hay un recursamiento que empieza a las 4 . Y no se va a su casa porque no tiene para volver. Esos casos pasan muchas veces que el maestro le da algo de comer, compra algo extra y o, si tienes su taller deportivo más en la tarde, hay que ver cómo ayudar. Pasa mucho. De poquito en poquito, eso logra muchas veces que el alumno no se va (MITCHEL, em conversação, 2018).

horário da escola é de 7:00 às 13:00 ou até 14:30, no entanto, às quintas e sextas-feiras os alunos ficam até mais tarde porque tem atividades de trabalho social ou esportivas ${ }^{12}$ ou caso tenham alguma recuperação por fazer. As atividades de recuperação são para os estudantes que não obtiveram o mínimo de 70 pontos em cada disciplina e, por isso, não foram aprovados ao final do semestre. No total, as recuperações acontecem em umas 8 e 9 sessões, ou seja, em 3 ou 4 semanas de trabalho extra, em que o estudante volta a estudar os conteúdos, fazer atividades e, ao final, realiza uma avaliação ${ }^{13}$. As recuperações acontecem durante as férias de inverno ou verão e em períodos de aula, quando acontecem diariamente das 13:00 às 14:30, 14:30 às 15:50 e de 15:50 às 17:10. A escola oferece a recuperação mesmo que seja para um único estudante. Estas aulas são ministradas pelos professores da escola ou, se estes já têm toda sua carga horária completa, a escola contrata outro professor para este trabalho.

Cada recuperação tem um custo para o aluno, o que é um problema para muitos estudantes da UABIC. Quanto têm mais de uma recuperação, eles 
podem pagar e fazer somente uma, deixando as demais para depois ${ }^{14}$, pois as disciplinas não são consecutivas. Ou seja, um estudante pode passar à seguinte e estar devendo a anterior, com exceção para o inglês do terceiro semestre. Neste caso, o estudante pode cursar inglês no quarto semestre junto com a recuperação do terceiro semestre, porém não será aprovado no quarto semestre se não tiver, antes, a aprovação do anterior. $\bigcirc$ aluno pode ter recuperações em todas as disciplinas que cursa e pode repetir a recuperação na mesma disciplina até 3 vezes, mas, se não for aprovado, é desligado da escola.

Continuando a explicação, o gestor acadêmico apontou outros fatores que, em sua opinião, com a chegada do MEFI, podem ter melhorado a frequência à escola e ajudado os estudantes a seguir seus estudos e não reprovar.

Hay un mayor seguimiento que trajo el MEFI por la parte de tutoría y orientación. Hay un programa ahorita que se llama "Yo no abandono"15, en cada clase, además de la lista normal del maestro, en cada salón, hay una hoja donde se marca su ausencia y la tutora los llama para conversar ${ }^{16}$ y, si el alumno falta, se les llama a los padres de familia. Eso empezó con el MEFI y nos ha apoyado mucho para evitar parte de la deserción porque a veces los papás no estaban enterados. El mismo modelo exige de alguna manera del profesor más trabajo: recibo la tarea, califico, retroalimento y, si hay algo que corregir, en teoría el profesor debería solicitar y recibir un email. Yo sé que no sucede siempre, pero ha aumentado esa solicitud. Y sí, veo a muchos que lo hacen. Eso permite que el alumno vaya mejorando un poco su calificación, pues, en el camino, va corrigiendo sus errores. Es mejor que, en el final, tenga que entregar todo de golpe. Otra actividad interna que hemos hecho: cuando vemos que algún chico está yendo mal que necesita recursamiento, a veces, preferimos descargarlo de ese recursamiento, como si no se hubiese inscrito y él sigue preparándose. Cuando se siente preparado, paga su extraordinario porque hay una mayor seguridad de que apruebe. Pero, todo eso lo manejamos de manera interna. Estoy seguro que, si aplicáramos la normativa como está planteada en el modelo, la deserción sería la misma. Por ejemplo, en los extraordinarios nos dicen que el alumno debe tener 100\% de asistencia. Si ya reprobaste tu asignatura, cuando vas a un recursamiento, no debes faltar ni una vez, pero no aplicamos eso, tenemos extendido a tres faltas, a la tercera falta, ya te doy de baja, pero desde la primera falta el profesor tiene que enviar un correo a la tutora y a mí y nosotros lo llamamos para saber lo que está pasando, en la 
segunda falta, volvemos a llamar y en la tercera falta ya damos de baja. Son esas pequeñas acciones que tratamos de hacer todos los días, para evitar eso y nos ha funcionado. Puede ser que hay otro factor, no lo dudo, esos son al menos los que yo he podido ver directamente (MITCHEL, em conversação, 2018).

Os comentários revelam um interesse muito grande da escola por cada um dos estudantes, buscando uma proximidade que facilita o apoio, inclusive em suas dificuldades financeiras. Além do mais, chama a atenção que a escola tome uma atitude interna de alterar ou flexibilizar algumas regras da UADY por conhecer a realidade dos seus estudantes e fazer todos os esforços para que sigam em seus estudos. Mitchel nos disse que, com o MEFI, diminuiu também a reprovação:

Comparado con el modelo anterior, ha disminuido la reprobación. Digamos que al final de un semestre, en el modelo anterior, de 300 alumnos, teníamos 250 que al menos debían una asignatura. Ahorita, con él MEFI, nuestro mejor número ha sido, que, al término de un semestre, eran 80 a 85 alumnos que debían 1 asignatura. Sí, redujo casi al 50\% (MITCHEL, em conversação, 2018).

A respeito dos resultados gerais da escola, segundo o gestor acadêmico, na avaliação do Pisa ${ }^{17}$, houve uma geração de estudantes que obteve dois pontos acima da média das outras escolas de ensino médio mexicanas. No entanto, as demais gerações da escola estão no $35^{\circ}$ lugar a nível estatal, sendo 50 a posição mais baixa em que já estiveram:

Fíjese qué curioso porque las otras dos prepas de la UADY, la prepa 1 y la prepa 2, se ubican en los tres primeros lugares y llama mucho la atención que nosotros, siendo una tercera prepa de UADY con el mismo plan de estudios, nos quedamos en un lugar 35, no hemos podido acercarnos. Hay muchos factores, hemos querido de alguna manera justificar el porqué, pero hay que investigar por qué pasa eso (MITCHEL, em conversação, 2018).

Por outro lado, também há alguns bons resultados e, recentemente, alguns alunos estão começando a ter participação em Olimpíadas como de matemática e de química. "Son pocos alumnos todavía, pero ya empiezan a destacarse algunos." (MITCHEL, em conversação, 2018). É uma grande conquista também que estudantes, que talvez não fizessem sequer o ensino médio, 
consigam fazer curso superior e alguns sejam aprovados para estudar na universidade considerada a melhor do estado.

El diría que al menos uno 50\% logran ingresar una carrera de UADY y terminan. Al menos, los que han regresado, regresan contentos. Muchos, sobre todo de las primeras generaciones, nos platican que, en sus carreras, eran muy reconocidos por sus maestros que decían que tenían buenas habilidades de expresión, de investigación, de trabajo en equipo, comparados con los de otras prepas (MITCHEL, em conversação, 2018).

Diana, por outro lado, nos contou que, nas primeiras duas gerações da escola, 50\% dos estudantes que tentavam estudar na UADY eram aprovados, uma boa porcentagem devido ao nível de competição da prova. No entanto, na geração do novo modelo educativo, esse número reduziu para $30 \%$ e eles estão tentando saber o que está acontecendo, depois da mudança do modelo. Ou seja, com o MEFI se reduziu a reprovação na escola, porém se reduziu também os índices de aprovação na UADY. Uma das indicações de qualidade da escola pode ser, seguramente, seus índices de aprovação na universidade $^{18}$, no entanto, nem todos os estudantes querem continuar estudando. Além disso, a missão da escola é mais ampla:

Formar bachilleres con una educación integral, humanista y de calidad, comprometidos con el desarrollo sustentable, innovadores, creativos, emprendedores, con una clara visión de su propio desarrollo personal y social, con conocimientos, principios y valores, que posean competencias para la vida y continuar su formación en el nivel superior, con capacidad para insertarse social y productivamente y así contribuir a su realización personal IMISIÓN DE LA ESCUELA, s.d.).

Para a realização destes propósitos, a UABIC tem uma matriz curricular muito interessante, que visa a formação integral do aluno. É muito claro que ela não tem como objetivo final a aprovação na universidade e sim uma preparação que possa ser útil aos estudantes em muitas áreas de sua vida, quando terminem o ensino médio. Há uma formação profissional lainda que pequena, pois não é uma escola técnica), uma formação humana muito significativa, com uma perspectiva de interação comunitária que mantém a escola e seus estudantes conectados com o seu bairro, e não fechados em suas salas 
de aula, visando unicamente seu benefício pessoal. Estas atividades podem ser simples para estudantes do ensino médio, porém os sensibiliza para observar o seu entorno, conhecê-lo e propor mudanças para si mesmos e para a população atendida que, no caso da escola, são as famílias, amigos e vizinhos dos próprios estudantes. Na UABIC, os estudantes fazem, obrigatoriamente, atividades sócio comunitárias em que atuam como agentes de mudanças para modificar seu entorno, realizando ações muito concretas para uma situação em que ele, ou pessoas de sua comunidade, podem estar vivendo.

\section{Matriz curricular da UABIC}

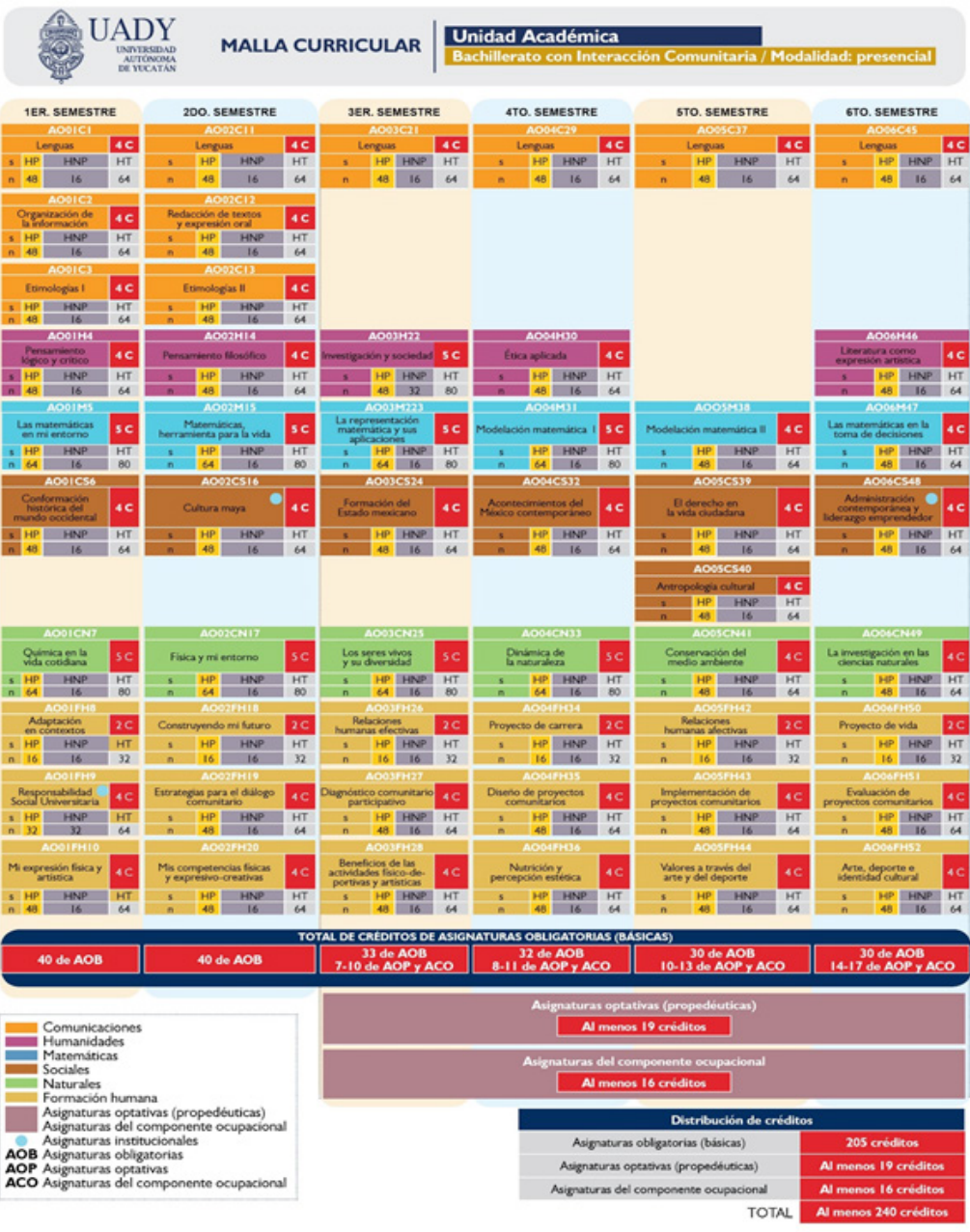

Imagem: PLAN de estudios del Bachillerato General Universitario. 
primeiro que me chamou a atenção é que os estudantes têm matérias optativas e algumas de caráter profissionalizante. Algumas disciplinas estabelecem relações entre os conteúdos e o cotidiano como: "Las matemáticas en mi entorno" e "Química en la vida cotidiana" e com o estudante como: "Proyecto de carrera", "Proyecto de vida" e "Relaciones humanas afectivas". Há todo um conjunto de matérias relacionadas com as atividades sociais que os estudantes desenvolvem na comunidade e os preparam tanto para a investigação como para a implementação de um projeto social comunitário.

Todas as disciplinas têm uma sequência, um programa geral, criado por professores da UADY e das 3 escolas da Universidade. $\bigcirc$ docente tem que preparar seu material, mas deve se basear em algo que está estruturado, e cada semestre há reuniões dom o gestor acadêmico com o objetivo de que as escolas desenvolvam o mesmo plano de estudos. Diana comenta que, algumas vezes, eles têm que fazer adequações, porque existem atividades não presenciais e muitos estudantes não tem computador ou internet.

Por suas exigências de participação e envolvimento, a escola demanda dedicação por parte dos estudantes e apoio de suas famílias. Mitchel nos contou que são realizadas reuniões com as famílias três vezes durante cada semestre e cerca de 80 a $90 \%$ dos familiares comparecem. As reuniões são nas salas de aula com os professores e os familiares. A escola apresenta a média de todas as disciplinas por turma, para que, com o boletim do filho, eles possam ver se ele está acima ou abaixo da média ${ }^{19}$. É um momento importante também para que os familiares tenham mais proximidade com os professores de seus filhos.

Y de la parte de la relación con los maestros, esta escuela, comparada con las otras dos de la misma UADY, tiene un vínculo muy cercano con los alumnos. Creo que es porque somos una escuela pequeña, los salones son de 30 a 33 alumnos y los maestros realmente llegan a hacer un lazo importante con ellos. Pues el contexto es una zona vulnerable o marginada. Para muchos de estos chicos, y me consta porque he oído que ellos lo digan abiertamente, los maestros son un modelo para seguir, son un ejemplo de vida y recuerdo. Frases muy significativas donde el alumno decía: yo no hubiese terminado la prepa, si no me hubiese inspirado tal maestro o tal maestra, porque a veces en casa no tienen ese apoyo constante, a veces por ignorancia o ausencia de los papás que no están. Aquí encuentran ellos la posibilidad de que sí se puede salir 
de este ciclo donde viven. Hay muy buenas relaciones con ellos, se ve en los pasillos, se saludan, el respeto entre los compañeros y los maestros es muy marcado. Tenemos de pronto ahí los casos donde hubo algún malentendido o algo, pero son casos mínimos. Normalmente, ellos saben estas cuestiones de respeto y los mismos maestros igual: si les pide que los promuevan, que los traten a todos igual. Hay que estar pendientes de estas cuestiones de bullying o de acoso con los alumnos y, a través del área tutoría, dale la atención. Entonces hay muy buena relación (MITCHEL, em conversação, 2018).

Conhecendo este caráter de proximidade nas relações entre estudantes e professores, buscamos saber como são as contratações para trabalhar na $\cup A B I C$. Alguns professores foram convidados, muitos deles ex-alunos da UADY e com perfil para o trabalho, mas a maioria foi contratada através de uma seleção em que houve uma convocação estatal, quando a escola ia ser aberta. Segundo Mitchel, houve mais de 200 candidatos e, no primeiro ano, foram contratados 8 professores e os demais foram chamados por seu currículo à medida em que a escola necessitava ${ }^{20}$. Todos os professores, desde 2009, são contratados por 6 meses e, a cada semestre, se renovam os contratos. 16 Na UADY, os professores têm que passar cerca de 10 anos para ter direito à estabilidade no cargo.

Es muy raro, es una excepción muy grande que, antes de los 10 años, den base ${ }^{21}$ a un profesor. Las personas que tienen base son las personas administrativas, los supervisores, las secretarias, la señora del control escolar que ve los trámites, los intendentes... ellos, a los 2 años, ya pueden aspirar a una base, pero los profesores de la UADY al menos tienen que esperar 10 años. Yo conozco caso de compañeros que después de 18 años llegó su base (MITCHEL, em conversação, 2018).

Os professores da UABIC podem ter, a qualquer momento, seus contratos encerrados, pois não há nenhuma garantia que eles vão permanecer no semestre seguinte ${ }^{22}$. No entanto, segundo nos informou Mitchel, até o momento, há um compromisso de manter o grupo e os profissionais que saíram da escola o fizeram por escolha pessoal, não por demissão. Eles acreditam que, em 2019, quando a escola faz 10 anos, pelo menos os professores fundadores vão obter estabilidade. 
Em relação aos salários, de acordo com Mitchel, os que trabalham em outras escolas públicas, que não são da UADY, normalmente ganham mais e a explicação é que os que dão aulas nas demais escolas públicas foram aprovados num concurso que thes dá estabilidade. Nestas escolas públicas, os professores não podem dar aulas se não tiverem passado por este concurso, na UADY sim. Por isso, um professor com carga horária integral em escolas estatais no México recebe mais que um professor da UADY. Para Mitchel, o docente da UABIC tem mais exigências de trabalho, pois, diferentemente das outras duas escolas, ela termina mais tarde as aulas. Além disso, Patricia nos comentou que, como as disciplinas da UABIC foram criadas pelo MEFI, quando querem preparar algo diferente, nem sempre os professores ${ }^{23}$ encontram materiais prontos e devem elaborar seus materiais de trabalho ${ }^{24}$ e ter tudo pronto no momento de iniciar o semestre.

A UABIC exige muita dedicação, tanto dos estudantes, quanto dos professores, por seguir o mesmo plano de estudos das outras duas escolas da UADY, pela grande expectativa de preparar os estudantes, por sua missão de promover uma formação integral e de alta qualidade, pelo trabalho social que desenvolve na comunidade e pelas condições dos estudantes e suas famílias.

\section{Considerações Finais}

A pesquisa, na perspectiva do construcionismo social, é sempre relacional e deve envolver os participantes em todas as etapas do trabalho. Eu assisti aulas com os estudantes, conversei com alguns profissionais, alunos e seus familiares sobre a escola e o que pensavam do trabalho da instituição. Nas conversações com os professores, eles foram convidados a dizer como era seu trabalho na escola e, a partir daí eu perguntava coisas que não me estavam claras ou curiosidades que tinha, a partir da fala deles. Os professores me pareciam muito à vontade falando do seu trabalho e as conversações foram livres, sem um questionário definido previamente. $\bigcirc$ artigo foi enviado à escola e os professores deram suas opiniões acerca do conteúdo. Alguns sugeriram mudanças e, depois de feitas as alterações, todos leram e concordaram com a publicação. Os novos encontros e conversações foram novas oportunidades de falar acerca do trabalho que faziam e de construirmos juntos a pesquisa. 
A UABIC tem uma história muito interessante e importante na cidade de Mérida e, em seus quase dez anos de existência busca adaptar-se a novas realidades e desafios, mas sempre mantendo sua missão de uma formação escolar integral.

Para o trabalho de formação social e humana que desenvolve esta escola de ensino médio, foi criada uma matriz curricular diferenciada com disciplinas que buscam articular os conteúdos à realidade dos estudantes, com matérias optativas, matérias de formação humana, de preparação para o trabalho e atividades sócio comunitárias.

A escola tem o desafio de promover uma educação de qualidade preparando estudantes de uma região com baixos recursos econômicos para a educação superior, comprometendo se também em formar seres humanos íntegros e responsáveis, interessados e preparados para se envolver na busca de transformações sociais.

Minha experiência nos dias em que estive na escola foi de que em tudo se busca oferecer o melhor para os estudantes e eles, assim como a comunidade, se sentem muito agradecidos e consideram que a escola brinda thes com uma formação de qualidade.

Por outro lado, a situação dos docentes da escola, com salários mais baixos que os professores estatais, necessitando de, pelo menos, dez anos de trabalho para obter estabilidade funcional, não é a ideal. Melhores salários para os professores são uma garantia importante, pois eles são fundamentais para a qualidade da educação e é visível a responsabilidade e dedicação com que realizam suas tarefas.

Uma das coisas a considerar também é, por sua seleção, dificilmente ingressam na UABIC alunos com muitas dificuldades de aprendizagem, déficit cognitivo ou outras deficiências. Está claro que foi uma decisão da escola receber estudantes com melhores condições de chegar à universidade. Estes, pela região em que vivem e, por suas condições financeiras, tinham menores possibilidades de estudar em uma escola da UADY. Houve uma flexibilização dos critérios para a seleção dos estudantes, mesmo assim continua sendo uma escola para poucos e penso que isso é algo a melhorar, afinal de contas, todos têm direito a uma educação de qualidade. 


\section{Notas}

1 Este artigo é parte de uma pesquisa de pós-doutorado feita no Instituto Kanankil na cidade de Mérida, no México. Agradeço às contribuições de María del Rocío Chaveste Gutierrez e Papusa - María Luisa Molina López pelas conversações tão agradáveis e de muita aprendizagem. Agradeço à Laura Cámara Bauserman por sua leitura e correção do espanhol.

2 Dedico este artigo à UABIC e agradeço ao coordenador administrativo Guillermo Contreras Gil pela confiança em permitir a pesquisa e a publicação do artigo com o nome da instituição, a todos os professores que cederam seu tempo e informações do seu trabalho e aos estudantes que me receberam em suas salas de aula e me ajudaram a compreender melhor como funciona a escola.

3 No México, as escolas com o nível de ensino médio são denominadas bachillerato preparatórias e chamadas comumente por "prepas".

4 Este artigo foi enviado a todos os participantes da pesquisa e ao diretor da escola para sua aprovação e a publicação foi condicionada a que eles estivessem de acordo com a redação. Todos os participantes foram convidados a participar e aceitaram gravar seus relatos. As fotos também foram feitas e publicadas com a aprovação da escola.

5 Mitchel dá aulas de redação de textos e organização da informação e, sempre tem uma turma: "[...] para que pueda vivir en la realidad y verlo directamente lo que me comenta los alumnos y los maestros" (MITCHEL, em conversação, 2018).

6 gestor acadêmico coordena os coordenadores das áreas de matemática, de ciências naturais, de ciências sociais, esportes e tecnologia.

7 Alguns profissionais são contratados para fazer alguns trabalhos, mas não são professores da escola. Estive, por exemplo, com duas pessoas que acompanhavam os trabalhos sócio comunitários dos estudantes e eram contratados somente para esta atividade.

8 As transcrições estão muito próximas ao original, algumas repetições e vícios de linguagem foram retirados.

9 Mitchel nos informou que uma das principais características do modelo é o trabalho a partir de competências, que já acontecia na Europa, na Austrália e em outros lugares e foi adoptada porque tinham muitos argumentos a favor.

10 Outras vezes vi os estudantes fazer vídeos pela escola e me pareciam ser para atividades de aula.

11 As aulas de inglês e matemática são as únicas em que os estudantes não podem sair nem sequer para ir a uma consulta nos consultórios de enfermagem, odontologia e nutrição na escola. A escola tem uma enfermeira contratada e os serviços de odontologia e nutrição são feitos por estudantes da UADY sob supervisão ou por profissionais fazendo serviços sociais.

12 Mitchel nos disse que, segundo suas últimas estatísticas, em torno de 30\% dos alunos trabalhavam em lojas, ou vendendo créditos de telefones celulares ou coisas assim. Perguntei aos estudantes como conciliam o horário da escola e de trabalho e eles me disseram que, na comunidade, seus patrões sabem que eles tem atividades escolares e que tem menos horas disponíveis para o trabalho.

13 Se o aluno é reprovado em uma disciplina, pode se tornar um aluno irregular, ou seja, tem que aprovar nas matérias que deve para entrar em aula e, muitas vezes, tem que incorporar à geração seguinte. 
Formação humana e social a partir da escola

14 Cada recuperação para cada disciplina tem um custo de $\$ 92$ pesos mexicanos para os estudantes da UABIC, mas nas outras duas escolas da UADY, o custo é de $\$ 492$ pesos.

15 O Programa "Yo no Abandono" foi criado em 2013 pela Secretaria de Educação Média Superior do México que disponibiliza, em seu site na internet, vários materiais, inclusive uma "caja de herramientas para una gestión contra el abandono escolar" a partir de um amplo movimento contra o abandono escolar.

16 Diana nos contou que a lista de frequência é recolhida todas as sextas-feiras, e às segundas, os tutores chamam os estudantes para uma explicação. Se eles não comparecem ou se faltam muito, as famílias são contatadas para saber o que está acontecendo.

17 PISA, Programa Internacional de Avaliação dos Alunos, qualifica, a cada três anos, os estudantes que estão terminando a educação obrigatória em três áreas distintas: leitura, matemática e ciências e faz uma comparação dos resultados em vários países do mundo.

18 Segundo a experiência de Mitchel, cerca de 30\% dos ex-alunos da UABIC foram estudar na UADY e alguns vão para faculdades particulares ou vão trabalhar e uma porcentagem mínima de alunas que deixam de estudar, se casam e tem filhos.

19 Estas reuniões são importantes também porque a escola tem uma visão de como estão as turmas, durante o transcurso do semestre.

20 Os que prestam serviços, como os psicólogos, em geral, não realizaram avaliações, foram selecionados por currículos e entrevistas. Cada profissional tem um contrato de trabalho diferente dependendo de seus horários de trabalho e suas funções.

21 Base significa estabilidade funcional e uma melhora do salário.

22 Há um diretor de todo o nível superior e médio da UADY que é o responsável pela contratação dos professores.

23 Patrícia nos informou que a escola está no sistema nacional que regula a qualidade da educação e, para isto, todos os professores tinham que obter uma certificação e estar preparados para trabalhar com competências e, portanto, mais de $90 \%$ dos professores da UABIC tem uma formação em competências docentes.

24 Segundo Patrícia, estes materiais são mais econômicos para os alunos, que podem tirar cópias deles.

\section{Referências}

ANDERSON, Harlene. Relaciones de colaboración y conversaciones dialógicas: Ideas para una práctica sensible a lo relacional. Family Process, Philadelphia, EUA, v. 51 , n. 1, p. $1-20,2012$.

DEFEHR, Janice. Investigación de acción dialógica: el fenómeno de agencia democrática y transformativa de la habilidad de respuesta. [s.d.]. Disponível em: <https:/ / www.taosinstitute. net/Websites/taos/images/AboutRelationalResearchNetwork/Investigacio\%CC\%8 1n\%20 de\%20accio\%CC\%8 1 n\%20dialo\%CC\%8 l gica,\%20DeFehr,\%20J._.pdf>. Acesso em: 20 nov. 2018. 
EXANI I. Exámenes Nacionales de Ingreso. s.d. Disponível em: http://www.ceneval.edu. mx/exani-i. Acesso em: 20 nov. 2018

DIANA Marisol Rodríguez Bastos. Conversación. Mérida (México), 20 set. 2018.

CENEVAL. Centro Nacional de Evaluación para la Educación Superior. Disponível em: <http://www.ceneval.edu.mx/>. Acesso em: 16 nov. 2018.

GERGEN, Kenneth J.; GERGEN, Mary. Reflexiones sobre la construcción social. Barcelona, Buenos Aires, México: Paidós, 2011.

HANAL PIXÁN. Disponível em: <http://www.yucatan.gob.mx/? p=hanal_pixan>. Acesso em: 23 nov. 2018

INFANTE, Cynthia Loreto Sosa. Ser mujer: diálogos intergeneracionales. 128f. Tesis de Maestría. Instituto Kanankil. Mérida, México, 2013.

MIRSU - Modelo Institucional de Responsabilidad Social Universitaria en la UADY. Disponível em: $\quad<h t t p: / / w w w . d g p l a n e i . u a d y \cdot m x /$ data/rsu/PRESENTACl\%C3\%93N\%2OMODELO. PDF>. Acesso em: 16 nov. 2018.

MISIÓN de la escuela. Disponível em: <http://www.unidadacademica.uady.mx/mision. php>. Acesso em: 20 nov. de 2018.

MITCHEL Antonio Guerrero González. Conversación. Mérida (México), 17 set. 2018.

PATRICIA del Rosario Baas Rejón. Conversación. Mérida (México), 7 set. 2018.

PLAN de estudios del Bachillerato General Universitario. Julio, 20 15. Disponível em: <http:// www.unidadacademica.uady.mx/userfiles/calendario/VEPLANBGU.pdf>. Acesso em: 22 nov. 2018.

RSU - Responsabilidad Social Universitaria. Disponível em: <http://www.dgplanei.uady. mx/rsu.php>. Acesso em: 16 nov. 2018

YO no abandono. Disponível em: <http://www.sems.gob.mx/es/sems/yo_no_abandono>. Acesso em: 22 nov. 2018.

Profa. Dra. Rita de Cássia de Souza Universidade Federal de Viçosa (Minas Gerais, Brasil) Departamento de Educação Grupo de Pesquisa: Memória, Instituições e Subjetividade (CNPq) ORCID ID: https: / / orcid.org/0000-0001-9823-6174 E-mail: ritasouza@ufv.br; ritasouzaufv@gmail.com Recebido 22 out. 2018 Aceito 14 jan. 2019 